Article

\title{
Tissue Proteome of 2-Hydroxyacyl-CoA Lyase Deficient Mice Reveals Peroxisome Proliferation and Activation of $\omega$-Oxidation
}

\author{
Youssef Khali1 ${ }^{1}(\mathbb{D})$, Sara Carrino ${ }^{1,2}\left(\mathbb{D}\right.$, Fujun Lin ${ }^{3,4}{ }^{(D)}$, Anna Ferlin ${ }^{3,5}\left(\mathbb{D}\right.$, Heena V. Lad ${ }^{6}$, Francesca Mazzacuva ${ }^{1,7}$, \\ Sara Falcone ${ }^{6}$ D , Natalie Rivers ${ }^{6}$, Gareth Banks ${ }^{6}$, Danilo Concas ${ }^{6}$, Carlos Aguilar ${ }^{6}$, Andrew R. Haynes ${ }^{6}$, \\ Andy Blease ${ }^{6}$, Thomas Nicol ${ }^{6}$, Raya Al-Shawi ${ }^{8}$, Wendy Heywood ${ }^{1}$, Paul Potter ${ }^{6}$, Kevin Mills ${ }^{1}$, Daniel P. Gale ${ }^{3,+}$ \\ and Peter T. Clayton $1, *,+(\mathbb{D}$
}

\section{check for}

updates

Citation: Khalil, Y.; Carrino, S.;

Lin, F.; Ferlin, A.; Lad, H.V.;

Mazzacuva, F.; Falcone, S.; Rivers, N.; Banks, G.; Concas, D.; et al. Tissue Proteome of 2-Hydroxyacyl-CoA Lyase Deficient Mice Reveals Peroxisome Proliferation and Activation of $\omega$-Oxidation. Int. J. Mol. Sci. 2022, 23, 987. https:// doi.org/10.3390/ijms23020987

Academic Editor: Johannes Berger

Received: 16 December 2021

Accepted: 11 January 2022

Published: 17 January 2022

Publisher's Note: MDPI stays neutral with regard to jurisdictional claims in published maps and institutional affiliations.

Copyright: (C) 2022 by the authors. Licensee MDPI, Basel, Switzerland. This article is an open access article distributed under the terms and conditions of the Creative Commons Attribution (CC BY) license (https:// creativecommons.org/licenses/by/ $4.0 /)$.
1 Genetics and Genomic Medicine, Great Ormond Street Institute of Child Health, University College London, London WC1N 1EH, UK; y.khalil@ucl.ac.uk (Y.K.); sara.carrino@studio.unibo.it (S.C.); f.mazzacuva@uel.ac.uk (F.M.); wendy.heywood@ucl.ac.uk (W.H.); kevin.mills@ucl.ac.uk (K.M.)

2 Department of Experimental, Diagnostic and Specialty Medicine, University of Bologna, 40138 Bologna, Italy

3 Department of Renal Medicine, University College London, London NW3 2PF, UK; linfujun@xinhuamed.com.cn (F.L.); a.ferlin@rbht.nhs.uk (A.F.); d.gale@ucl.ac.uk (D.P.G.)

4 Department of Nephrology, Xin Hua Hospital, School of Medicine, Shanghai Jiao Tong University, Shanghai 200082, China

5 Clinical Genetics and Genomics Laboratory, Royal Brompton Hospital, London SW3 6NP, UK

6 MRC Harwell Institute, Harwell Campus, Oxfordshire OX11 0RD, UK; h.lad@har.mrc.ac.uk (H.V.L.); sfalcone@well.ox.ac.uk (S.F.); n.rivers@har.mrc.ac.uk (N.R.); g.banks@har.mrc.ac.uk (G.B.); d.concas@har.mrc.ac.uk (D.C.); c.aguilar@har.mrc.ac.uk (C.A.); a.haynes@har.mrc.ac.uk (A.R.H.); a.blease@har.mrc.ac.uk (A.B.); tnicol@well.ox.ac.uk (T.N.); ppotter@brookes.ac.uk (P.P.)

7 Department of Bioscience, University of East London, London E15 4LZ, UK

8 Genetics Unit and Wolfson Drug Discovery Unit, Centre for Amyloidosis and Acute Phase Proteins, University College London, London NW3 2PF, UK; r.al-shawi@ucl.ac.uk

* Correspondence: Peter.clayton@ucl.ac.uk

+ These authors contributed equally to this work.

\begin{abstract}
Peroxisomal fatty acid $\alpha$-oxidation is an essential pathway for the degradation of $\beta$-carbon methylated fatty acids such as phytanic acid. One enzyme in this pathway is 2-hydroxyacyl CoA lyase (HACL1), which is responsible for the cleavage of 2-hydroxyphytanoyl-CoA into pristanal and formyl-CoA. Hacl1 deficient mice do not present with a severe phenotype, unlike mice deficient in other $\alpha$-oxidation enzymes such as phytanoyl-CoA hydroxylase deficiency (Refsum disease) in which neuropathy and ataxia are present. Tissues from wild-type and $\mathrm{Hacl1}^{-/-}$mice fed a high phytol diet were obtained for proteomic and lipidomic analysis. There was no phenotype observed in these mice. Liver, brain, and kidney tissues underwent trypsin digestion for untargeted proteomic liquid chromatography-mass spectrometry analysis, while liver tissues also underwent fatty acid hydrolysis, extraction, and derivatisation for fatty acid gas chromatography-mass spectrometry analysis. The liver fatty acid profile demonstrated an accumulation of phytanic and 2-hydroxyphytanic acid in the $\mathrm{Hacl1}^{-/}$- liver and significant decrease in heptadecanoic acid. The liver proteome showed a significant decrease in the abundance of Hacl1 and a significant increase in the abundance of proteins involved in PPAR signalling, peroxisome proliferation, and omega oxidation, particularly Cyp4a10 and Cyp4a14. In addition, the pathway associated with arachidonic acid metabolism was affected; Cyp2c55 was upregulated and Cyp4f14 and Cyp2b9 were downregulated. The kidney proteome revealed fewer significantly upregulated peroxisomal proteins and the brain proteome was not significantly different in $\mathrm{Hacl1}^{-/-}$mice. This study demonstrates the powerful insight brought by proteomic and metabolomic profiling of $\mathrm{Hacl1}^{-/-}$mice in better understanding disease mechanism in fatty acid $\alpha$-oxidation disorders.
\end{abstract}

Keywords: peroxisomes; PPARs; liver; proteomics; isoprenoids 


\section{Introduction}

The primary mechanism for fatty acid degradation involves $\beta$-oxidation, in which a multistep enzymatic pathway converts fatty acid chains into acetyl-CoAs and 2-carbon shorter fatty acyl-CoAs which can in turn undergo further $\beta$-oxidation. This mechanism is prevented in the presence of a methyl group on the $\beta$-carbon such as with the 3-methylbranched phytanic acid (3,7,11,15-tetramethyl hexadecanoic acid). In such case, a preceding peroxisomal $\alpha$-oxidation pathway is required in order to shorten phytanic acid by one carbon into pristanic acid (2,6,10,14-tetramethylpentadecanoic acid) which can then undergo $\beta$-oxidation (Figure 1). The fatty acid $\alpha$-oxidation pathway involves activation of phytanic acid to phytanoyl-CoA, hydroxylation by phytanoyl-CoA 2-hydroxylase (PHYH), cleavage of 2-hydroxyphytanoyl-CoA into pristanal and formyl-CoA by 2-hydroxyacyl CoA lyase (HACL1), and oxidation of pristanal to pristanic acid by an aldehyde dehydrogenase. Furthermore, pristanic acid with a $C-2$ in an $(R)$-configuration requires conversation to an (S)-configuration by $\alpha$-methylacyl-CoA racemase (AMACR) in order to then undergo $\beta$-oxidation [1]. Another pathway for fatty acid degradation is through $\omega$-oxidation, in which dicarboxylic acids are formed and subsequently undergo $\beta$-oxidation from the omega end [2]. This pathway is catalysed by CYP450 enzymes and the peroxisomal $\beta$-oxidation pathway which are regulated by peroxisome-proliferator-activated receptor $\alpha(\operatorname{PPAR} \alpha)[3,4]$.

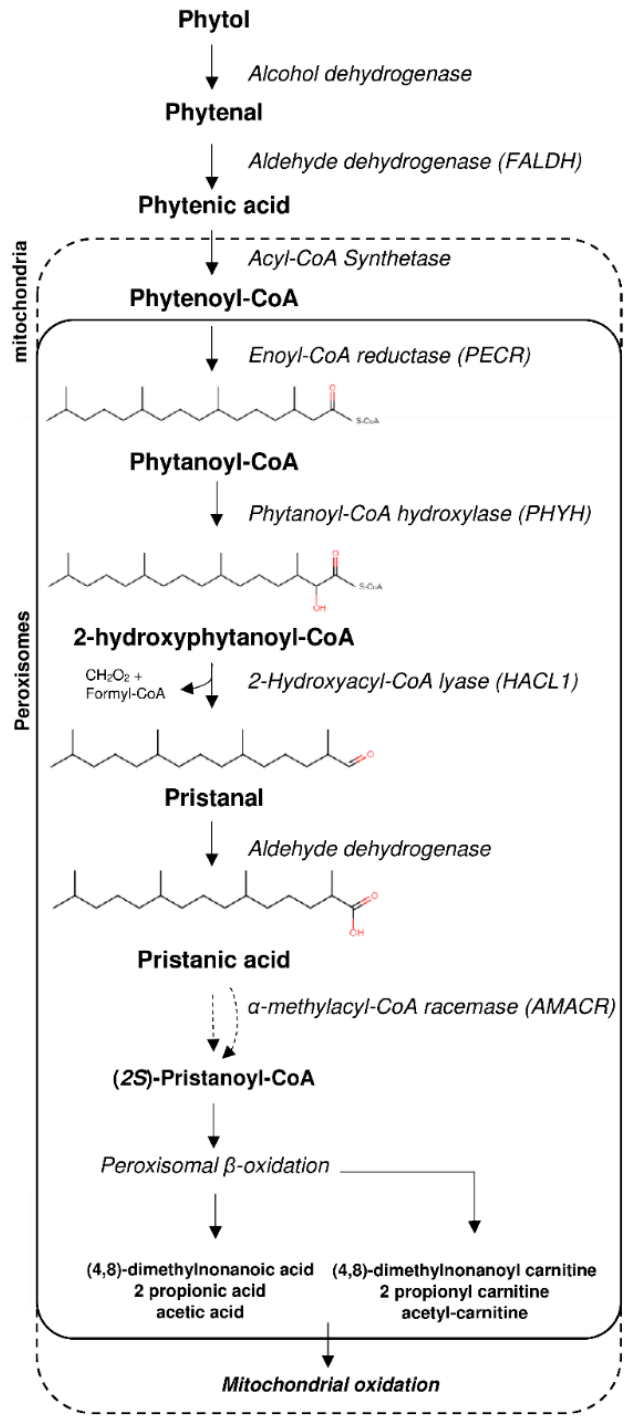

Figure 1. Phytol degradation pathway via peroxisomal alpha-oxidation. 
The phenotype of HACL1 deficiency in human (if any) has yet to be delineated but other inborn errors in the $\alpha$-oxidation pathway have been identified. Phytanoyl-CoA 2-hydroxylase deficiency, known as (adult) Refsum disease, leads to phytanic acid accumulation and affected individuals develop neuropathy, ataxia, and retinitis pigmentosa [5]. Since phytanic acid is strictly exogenous, mainly derived from ruminant animals and fish [6], patients who undergo dietary restriction of phytanic acid can lower their plasma phytanic acid levels, and reduce some of the clinical manifestations [7,8]. A similar phenotype is manifested in patients with AMACR deficiency, in which pristanic acid and phytanic acid accumulate [5]. The mouse model of Refsum disease on a high phytol diet presents with a phenotype similar to that of humans, including neuropathy and ataxia, along with accumulation of phytanic acid [9]. Amacr-deficient mice fed a high phytol diet show an accumulation of pristanic and phytanic acid and a significantly reduced lifespan as a result of hepatic failure, renal dysfunction, and brain lesions [10]. In contrast, Hacl1 knockout mice do not develop neurological disease when fed a high phytol diet; rather, in one study, they show weight loss, absence of abdominal white adipose tissue, an enlarged mottled liver, and reduced hepatic glycogen and triglycerides [11]. Immunohistostaining of mouse $\mathrm{Hacl1}^{-/-}$liver reveals the induction of the PPAR $\alpha$-target CYP4A1 involved in the $\omega$-oxidation pathway [11]. This alternative pathway and evidence of a yet unidentified endoplasmic reticulum lyase in the central nervous system [11] may explain the lack of a severe phenotype.

To date, there has only been one study published that shows evidence of PPAR $\alpha$ activation in $\mathrm{Hacl1}^{-/-}$mouse liver [11]. Here, we performed proteomic analyses on $\mathrm{HaCl1}^{-/-}$mouse liver, kidney and brain after feeding on a high phytol diet. We identified tens of proteins that were up- or downregulated in the liver, providing more insight on the activation of the $\omega$-oxidation alternative pathway and other pathways regulated by $\operatorname{PPAR} \alpha$.

\section{Materials and Methods}

\subsection{Animals}

A transgenic mouse strain (C57BL/6NTac-Hacl1tm1a(KOMP)Wtsi) harbouring the 'knockout-first' conditional cassette [12] in the Hacl1 gene was obtained from the European Mutant Mouse Archive. At week 3 after birth, 4 groups (male knockout $\left(\mathrm{Hacl1}^{-/-}\right)$, male wild-type $\left(\mathrm{Hacl1}^{+/+}\right)$, female knockout $\left(\mathrm{Hacl1}^{-/-}\right)$and female wild-type $\left(\mathrm{Hacl1}^{+/+}\right)$each comprising 10 individuals were weaned onto standard compressed Western diet that was replaced with phytol-enriched $(0.2 \% v / v)$ Western diet (both obtained from Research Diets Inc., New Brunswick, NJ, USA,) at week 6. Over a further 6-week period, body weight, markers of renal function, acoustic brainstem, fear conditioning, locomotor activity responses and optical coherence tomography were performed as previously described [13]. Tissues were isolated immediately after death and blotted proteins were probed with rabbit polyclonal antibodies (Cat. LS-C137258) obtained from LSBio (Seattle, WA, USA). Mice were maintained in the Mary Lyon Centre in Harwell UK, in specific pathogen-free conditions, with environmental conditions as outlined in the Home Office Code of Practice. Home Office ethical approval was granted under project licence 30/3070 and mice were euthanized by Home Office Schedule 1 methods. Welfare end points included chronic weight loss exceeding $20 \%$, or rapid weight loss of no more than $15 \%$, and excessive urination as well as general indicators of health. All procedures were carried out according to UK Home Office regulations, those laid out in the project license (30/3070), and local ethical guidelines.

\subsection{Materials}

Phytanic acid, urea, thiourea, iodoacetamide, 1,4-Dithioerythritol, Tris base, nonionic detergent octylphenoxy poly(ethyleneoxy)ethanol (IGEPAL ${ }^{\circledR}$ CA-630), and zwitterionic detergent Amidosulfobetaine-14 (ASB-14) were purchased from Sigma-Aldrich. LysC/Trypsin was purchased from Promega (UK). MTBSTFA + 1\%TBDMS (N-Methyl- 
$\mathrm{N}$-(tert-butyldimethylsilyl)trifluoroacetamide, Tertbutyldimetheylchlorosilane) was purchased from Thermofisher Scientific. Heptadecanoic-17,17,17-d3 acid was purchased from Qmx laboratories Ltd. (Essex, UK). 2-hydroxyphytanic acid was purchased from LGC (Middlesex, UK). All proteomic solvents were of UPLC grade. All lipid analysis solvents were of HPLC grade. All other reagents were of analytical grade.

\subsection{Preparation of Mouse Liver for Fatty Acid Analysis}

Fresh frozen liver tissues (wild-type $n=5 ; \mathrm{Hacl1}^{-/-} n=5$ ) were weighed and $120 \mathrm{mg}$ tissue were added to $1 \mathrm{~mL}$ homogenisation medium containing $50 \mathrm{mmol} / \mathrm{L}$ ammonium bicarbonate $+2 \%$ IGEPAL CA-630. Tissues were then homogenised using a Minilys tissue homogeniser (Bertin Instruments, Montigny-le-Bretonneux, France) for $4 \times 30 \mathrm{~s}$ intervals while placed on ice for $30 \mathrm{~s}$ in between intervals. The homogenates were stored at $-80{ }^{\circ} \mathrm{C}$ for later analysis.

\subsection{Fatty Acid Extraction and Derivatisation}

Two hundred microliters of tissue homogenate were mixed with $5 \mu \mathrm{L}$ of $50 \mu \mathrm{mol} / \mathrm{L}$ heptadecanoic-17,17,17-d3 acid as an internal standard. The samples then underwent acid hydrolysis in $2 \mathrm{~mL} 0.5 \mathrm{M} \mathrm{HCl}$ in acetonitrile for $45 \mathrm{~min}$ at $100^{\circ} \mathrm{C}$ followed by alkaline hydrolysis with $2 \mathrm{~mL}$ of $1 \mathrm{~mol} / \mathrm{L} \mathrm{NaOH}$ in methanol for $45 \mathrm{~min}$ at $100^{\circ} \mathrm{C}$. After samples were cooled down at room temperature, they were acidified with $250 \mu \mathrm{L} 6 \mathrm{M} \mathrm{HCl}$ followed by two-stage fatty acid hexane extraction with $2 \mathrm{~mL}$ hexane. The hexane solution was dried down using a stream of nitrogen. The fatty acids were then derivatised using $50 \mu \mathrm{L}$ MTBSTFA $+1 \%$ TBDMS for $30 \mathrm{~min}$ at $60^{\circ} \mathrm{C}$. For quantitation, a calibration line was created using 2-hydroxyphytanic acid and phytanic acid with heptadecanoic-17,17,17-d3 acid as the internal standard.

\subsection{GC-MS Fatty Acid Analysis}

An Agilent GC-MS system (GC 6890A and MS 5973) was used equipped with an HP-1MS capillary column ( $30 \mathrm{~m} \times 250 \mu \mathrm{m}$ i.d., $0.25 \mu \mathrm{m}$ film thickness). The GC temperature program was as follows: Initially $120^{\circ} \mathrm{C}$ increased to $200{ }^{\circ} \mathrm{C}$ at a rate of $20^{\circ} \mathrm{C} / \mathrm{min}$ followed by $2{ }^{\circ} \mathrm{C} / \mathrm{min}$ increase rate to $300{ }^{\circ} \mathrm{C}$ with a total run time of $60 \mathrm{~min}$. Samples were injected at a temperature of $250{ }^{\circ} \mathrm{C}$ in splitless mode. Data were acquired by scan mode $(\mathrm{m} / \mathrm{z}$ range $50-700)$ and selected ion monitoring (SIM). The SIM masses were as follows: Pentadecanoic acid-TBDMS = m/z 299; Heptadecanoic acid-TBDMS = m/z 327; D3heptadecanoic acid-TBDMS = m/z 330; Phytanic acid-TBDMS = m/z 369; 2-hydroxyphytanic acid-TBDMS $=\mathrm{m} / \mathrm{z} 499$.

\subsection{Preparation of Mouse Liver, Kidney, and Brain Tissues for Proteomic Analysis}

Fresh frozen mouse tissues (wild-type $n=3 ; \mathrm{Hacl1}^{-/-} n=3$ per tissue) were homogenised in $500 \mu \mathrm{L}$ homogenization buffer $(100 \mathrm{mmol} / \mathrm{L}$ Tris, $6 \mathrm{~mol} / \mathrm{L}$ urea, $2 \mathrm{~mol} / \mathrm{L}$ thiourea, 2\% ASB-14, pH 7.8) with protease inhibitor cocktail using a Minilys tissue homogeniser. Tissues were homogenised for $4 \times 30 \mathrm{~s}$ intervals while placed on ice for $30 \mathrm{~s}$ in between intervals. Samples were then centrifuged for $30 \mathrm{~s}$ and the supernatant transferred to $1.5 \mathrm{~mL}$ Eppendorf tubes for further centrifugation at $14,000 \times \mathrm{g}$ for $30 \mathrm{~min}$ at $4{ }^{\circ} \mathrm{C}$. A hundred microliters of the supernatant were then used for chloroform $/$ methanol protein precipitation with the remaining homogenate stored at $-80^{\circ} \mathrm{C}$.

\subsection{Protein Precipitation}

With a starting volume of $100 \mu \mathrm{L}$ homogenate, $400 \mu \mathrm{L}$ methanol were added and mixed followed by addition of $100 \mu \mathrm{L}$ chloroform and mixing, and finally topped up with $300 \mu \mathrm{L} \mathrm{H}_{2} \mathrm{O}$. The solution was centrifuged at $14,000 \times g$ for 2 min after which the top aqueous layer was discarded. Further $400 \mu \mathrm{L}$ methanol were added and mixed then centrifuged at $14,000 \times g$ for $3 \mathrm{~min}$. The methanol was discarded and the samples were dried by SpeedVac. The pellets were resuspended in $100 \mu \mathrm{L}$ digest buffer 
(100 mmol/L Tris, $6 \mathrm{~mol} / \mathrm{L}$ urea, $2 \mathrm{~mol} / \mathrm{L}$ thiourea, 2\% ASB-14, $\mathrm{pH} 7.8)$ and shaken for $2 \mathrm{~h}$ at room temperature.

\subsection{Protein Digestion}

Twenty microliters of lysate were reduced with $1.5 \mathrm{uL}$ of $195 \mathrm{mmol} / \mathrm{L} 1$,4-Dithioerythritol for $30 \mathrm{~min}$ at $37^{\circ} \mathrm{C}$ followed by alkylation with $195 \mathrm{mmol} / \mathrm{L}$ iodoacetamide for $30 \mathrm{~min}$ at room temperature in darkness. The solution was diluted with $155 \mu \mathrm{L}$ deionised $\mathrm{H}_{2} \mathrm{O}$ and $20 \mu \mathrm{L}$ of $1 \mu \mathrm{g} / 10 \mu \mathrm{L}$ LysC/Trypsin were added. The samples were incubated for $24 \mathrm{~h}$ at $37{ }^{\circ} \mathrm{C}$ with gentle shaking. The peptides were desalted by $\mathrm{C} 18$ cartridge solid phase extraction and lyophilised before reconstitution in $200 \mu \mathrm{L} \mathrm{3} \%$ Acetonitrile $+0.1 \%$ Formic acid solution.

\subsection{LC-MS Proteomic Analysis}

Samples were analysed using a QToF SYNAPT G2-Si mass spectrometer coupled to a NanoAcquity UPLC system (Waters Corp, Wilmslow, UK) using the previously described method [14]. Briefly, the liver and kidney peptide samples were analysed using an on-line two dimensional high/low $\mathrm{pH}$ LC setup. An amount of $4 \mu \mathrm{L}$ of peptide solution was injected and fractionated on an XBridge Peptide ethylene bridged hybrid C18 NanoEase Column $(130 \AA, 5 \mu \mathrm{m}, 300 \mu \mathrm{m} \times 50 \mathrm{~mm})$ using mobile phase A of $20 \mathrm{mmol} / \mathrm{L}$ ammonium formate, $\mathrm{pH} 9$ and mobile phase $\mathrm{B}$ of acetonitrile. The sample was fractionated by injecting into the XBridge Peptide column with 3\% mobile phase B, and then using a 4 min gradient up to the following mobile phase B percentages (liver, 4 fractions: $11.8 \%, 15.3 \%, 19.3 \%$ and 50\%; kidney, 6 fractions: 10.1\%, 13.1\%, 15.3\%, 17.7\%, 21.2\%, and 70\%). Following elution from the XBridge peptide column, each fraction entered an ACQUITY UPLC Peptide ethylene bridged hybrid C18 nanoACQUITY Column (10 Kpsi, $130 \AA$ A, $1.7 \mu \mathrm{m}$, $75 \mu \mathrm{m} \times 150 \mathrm{~mm}$ ) (Waters Corp, Wilmslow, UK) at a flow of $400 \mathrm{~nL} / \mathrm{min}$ and maintained at $35{ }^{\circ} \mathrm{C}$, and was then eluted with mobile phase $\mathrm{A}$ of $0.1 \% v / v$ formic acid with $5 \% v / v$ dimethyl sulphoxide and mobile phase B of $0.1 \% v / v$ formic acid in $100 \%$ acetonitrile with $5 \% v / v$ dimethyl sulphoxide. The gradient started at 3\% mobile phase B reaching $40 \%$ after $40 \mathrm{~min}$, increasing to $85 \%$ by minute 42 and kept for $2 \mathrm{~min}$ before returning to $3 \%$ at $45 \mathrm{~min}$ until $60 \mathrm{~min}$. The brain peptides were analysed by one dimensional LC setup by injection into the Peptide ethylene bridged hybrid C18 column without the fractionation step.

\subsection{Proteomic MS Data Analysis}

The mass spectra were analysed using Waters Progenesis QI for Proteomics software. Protein identifications were accepted with 2 peptides including 1 unique peptide, or at least 3 peptides with no unique peptide. Protein identities were searched against a mouse proteins database downloaded from uniport.org. Peptide identification parameters allowed for 2 missed cleavages, a maximum protein mass of $800 \mathrm{kDa}$, and modifications of $\mathrm{C}$ carbamidomethylation, $\mathrm{N}$ and $\mathrm{Q}$ deamidation, $\mathrm{M}$ oxidation, and pyrrolidone carboxylate. The false detection rate was set to less than $4 \%$, with ion matching requirements of 3 fragments per peptide, 5 fragments per protein, and 1 peptide per protein. Normalisation of ion abundance across the samples was performed using Progenesis QI. Differentially expressed proteins were chosen based on a minimum 1.5-fold change and $p$-value $<0.01$. Protein-protein interaction, KEGG pathway analysis, and gene ontology enrichment analysis were performed using Metascape.org [15] and DAVID Bioinformatics database 6.8. The protein networks were mapped using Cytoscape (v3.8.2).

\subsection{Statistical Analysis and Data Plotting}

All statistical tests were performed using OriginPro 2020 v9.7 (OriginLab Corp, Northampton, MA, USA). Graphs were plotted using OriginPro 2020 v9.7, Microsoft Excel (2016), and VolcaNoseR [16]. 


\section{Results}

\subsection{Hacl1 ${ }^{-/-}$Mouse Phenotype}

$\mathrm{Hacl1}^{-/-}$mice did not show Hacl1 protein in liver, kidney, brain, or heart when analysed by Western blot (Figure S1). The $\mathrm{Hacl1}^{-/-}$mice were apparently healthy, with no obvious phenotypic abnormalities and with no differences from the wild-type littermate controls observed, with or without a phytol-enriched diet. Over a 6-week period, no consistent differences in body weight, markers of renal function (Figure S2), acoustic brainstem (Figure S3A), fear conditioning (Figure S3B) or locomotor activity responses (Figure S3C) were observed between the wild-type and knockout animals. Optical coherence tomography revealed a similar proportion of homozygotes (12/26) compared with controls $(4 / 14)$ with abnormalities $(p=0.33)$ (Figure S4).

\subsection{Fatty Acid Profile in Hacl1-/- Mouse Liver}

Phytanic acid and 2-hydroxyphytanic acid concentrations were measured in the livers of wild-type and $\mathrm{HaCl1}^{-/-}$mice fed a high phytol diet. Both fatty acids were significantly elevated in $\mathrm{Hacl1}^{-/-}$liver $(p<0.01)$ (Figure 2$)$. In contrast, the odd chain fatty acid heptadecanoic acid was significantly reduced $(p<0.01)$ (Figure S5). These are in agreement with previously reported findings in Hacl1 deficient mouse liver [11].

\section{2-hydroxyphytanic acid}

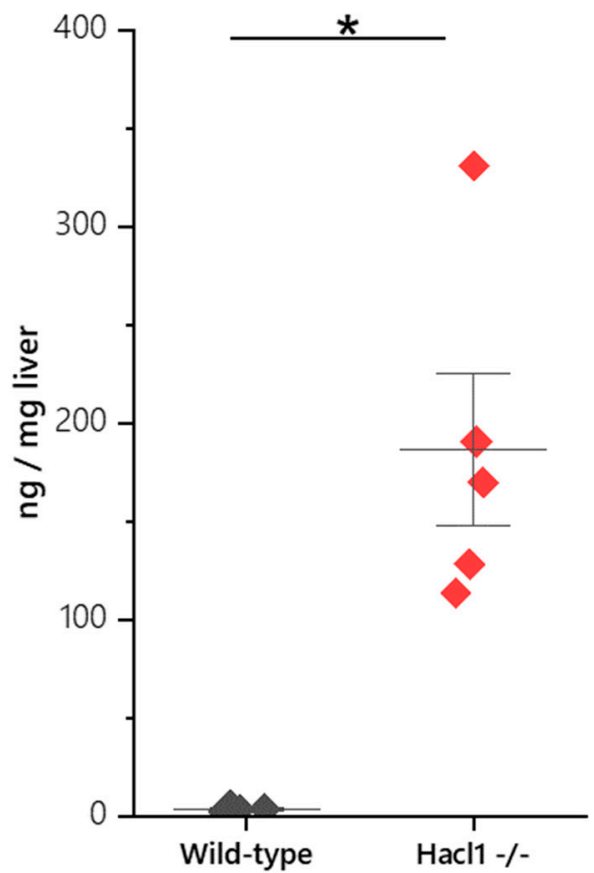

Phytanic acid

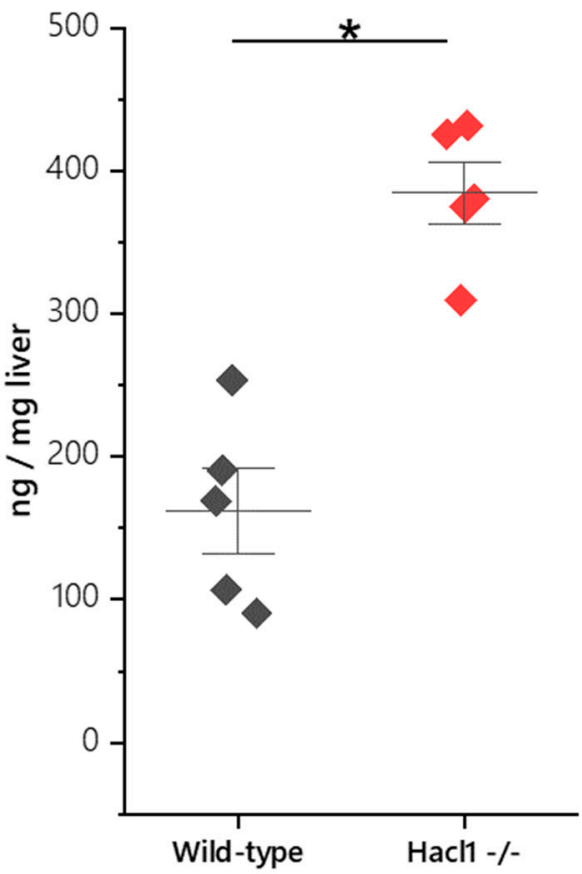

Figure 2. Phytanic acid and 2-hydroxyphytanic acid concentrations in mouse liver. Both fatty acids are significantly elevated in $\mathrm{Hacl1}^{-/-}$liver (* indicates $p<0.01$ ).

\subsection{Hacl1 ${ }^{-/-}$Mouse Liver Proteome}

We compared the liver proteome of wild-type and $\mathrm{Hacl1}^{-/-}$mice fed a high phytol diet. A total of 3136 proteins were identified, of these, 2646 proteins with at least 1 unique peptide. Using Progenesis QI for proteomics, the normalised abundance of each protein was compared in the wild-type and $\mathrm{Hacl1}^{-/-}$and 180 proteins were found to be differentially regulated by a minimum of 1.5 -fold $(p<0.01$ ) (Figure $3 \mathrm{~A}, \mathrm{~B})$. Of these, 142 proteins were upregulated, and 38 proteins were downregulated in $\mathrm{Hacl1}^{-/-}$liver (Figure S6). The Hacl1 peptides were identified in both wild-type and knockout livers and with a 44-fold decrease in normalised abundance in the knockouts (Figure 3C). As the Hacl1 protein was not detected by Western blot in the knockouts (Figure S1), the presence of these peptides is 
likely as a result of leaky expression from the knockout cassette or the presence of a low amount of full-length or truncated protein produced by exon skipping.

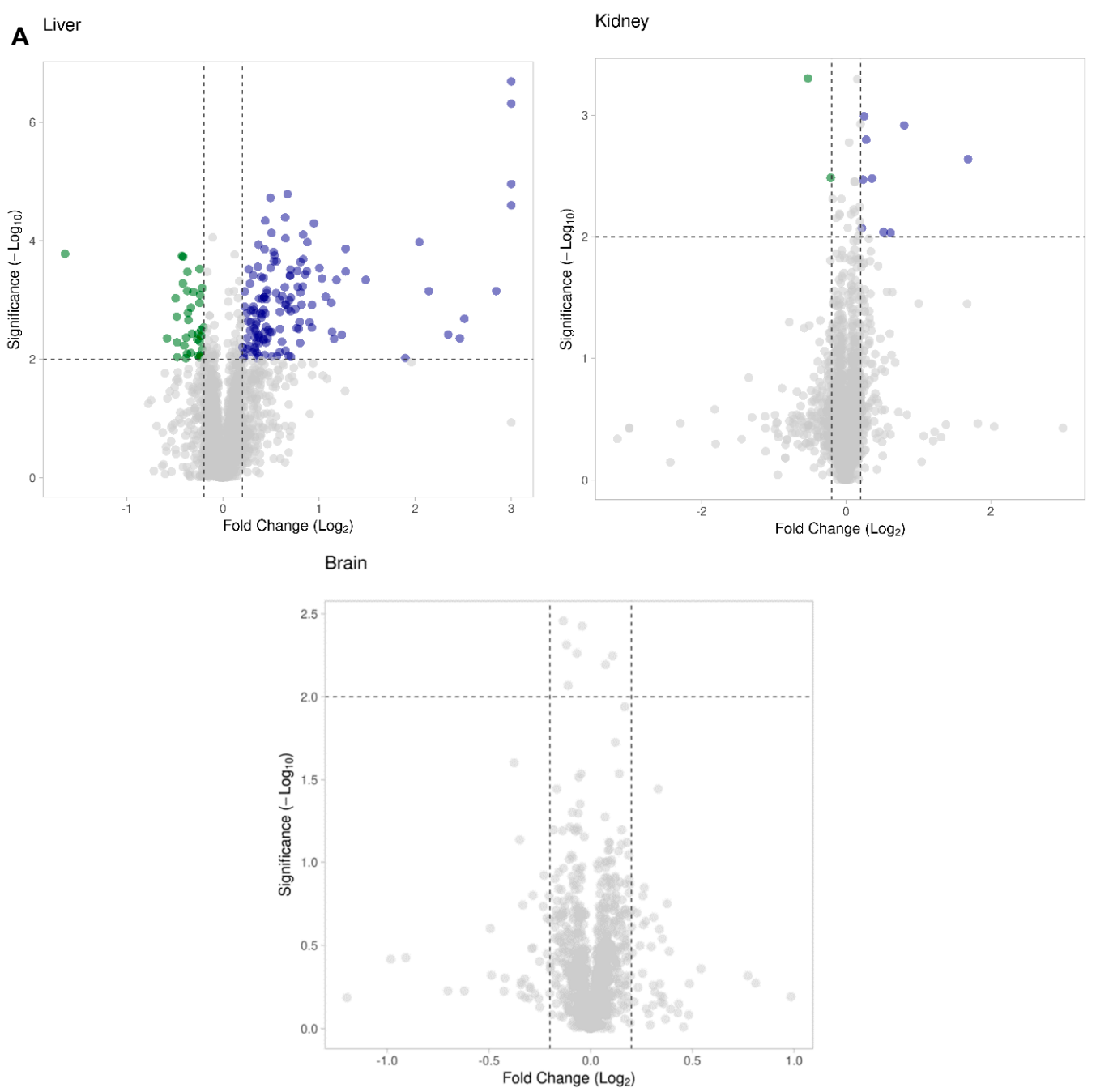

B

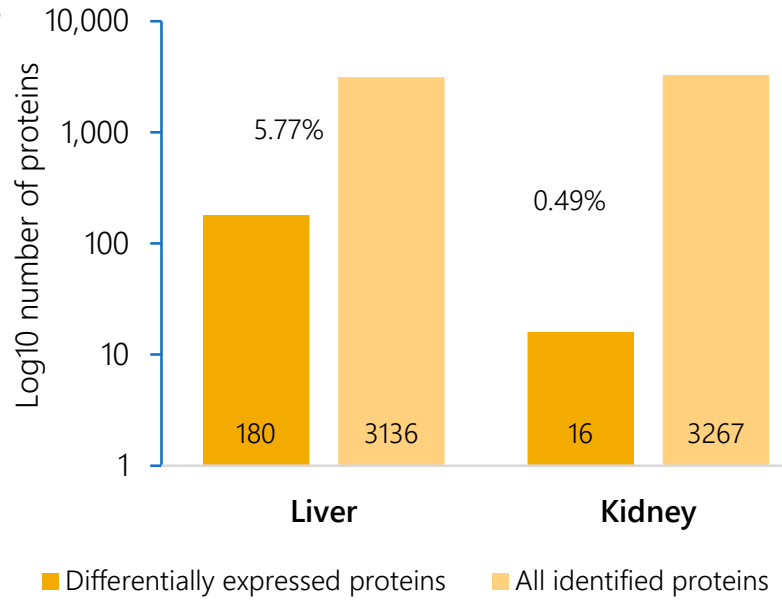

Liver Hacl1

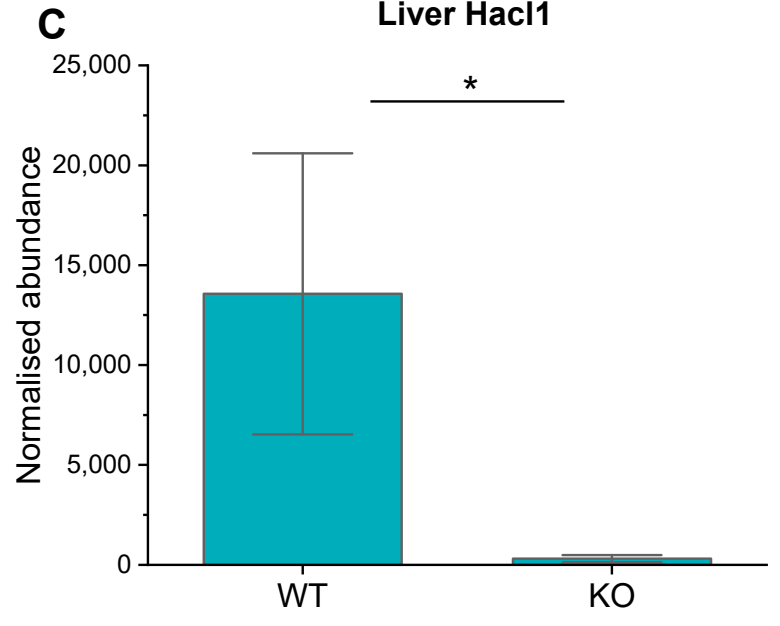

Figure 3. Proteomic analysis of $\mathrm{Hacl1}^{-/-}$mouse tissue. (A) Scatter plot of proteins identified and their fold change in $\mathrm{Hacl1}^{-/-}$liver, kidney, and brain tissue compared to wild-type. Proteins with 1.5-fold change $(p<0.01)$ were chosen as significantly differentially regulated. (B) Percentage of differentially expressed proteins in $\mathrm{Hacl1}^{-/-}$liver and kidney. (C) Hacl1 peptide abundance in mouse liver (* indicates $p<0.01$ ). 
Metascape analysis of pathway and process enrichment revealed that biological processes such as the Acyl-CoA metabolic process, carboxylic acid biosynthetic process, peroxisome organisation, and unsaturated fatty acid metabolic process were enriched in upregulated proteins (Figure 4). The KEGG pathway analysis of the upregulated proteins revealed 25 proteins were associated with metabolic pathways; of these, 22 and 8 proteins were associated with the peroxisome and PPAR signalling pathway, respectively, with statistical significance $(p<0.01)$ (Table 1). Biological processes enriched in the downregulated proteins include the long-chain fatty acid metabolic process, xenobiotic metabolic process, and cilium assembly (Figure 4).

\section{Enriched pathways and processes for upregulated proteins in $\mathrm{Hacl} 1^{-/}$mouse liver}

\section{ko04146 Peroxisome \\ ko00071 Fatty acid degradation}

GO:0006637 acyl-CoA metabolic process

GO:0046394 carboxylic acid biosynthetic process

GO:0007031 peroxisome organization

R-MMU-389887 Beta-oxidation of pristanoyl-CoA

GO:0033559 unsaturated fatty acid metabolic process

R-MMU-9603798 Class I peroxisomal membrane protein import

GO:1901615 organic hydroxy compound metabolic process

WP336 Fatty acid biosynthesis

GO:0034754 cellular hormone metabolic process

R-MMU-9012999 RHO GTPase cycle

GO:0042537 benzene-containing compound metabolic process ko00380 Tryptophan metabolism

GO:0043112 receptor metabolic process

GO:0006476 protein deacetylation

GO:0055088 lipid homeostasis

GO:0051225 spindle assembly

GO:0006084 acetyl-CoA metabolic process GO:0014047 glutamate secretion

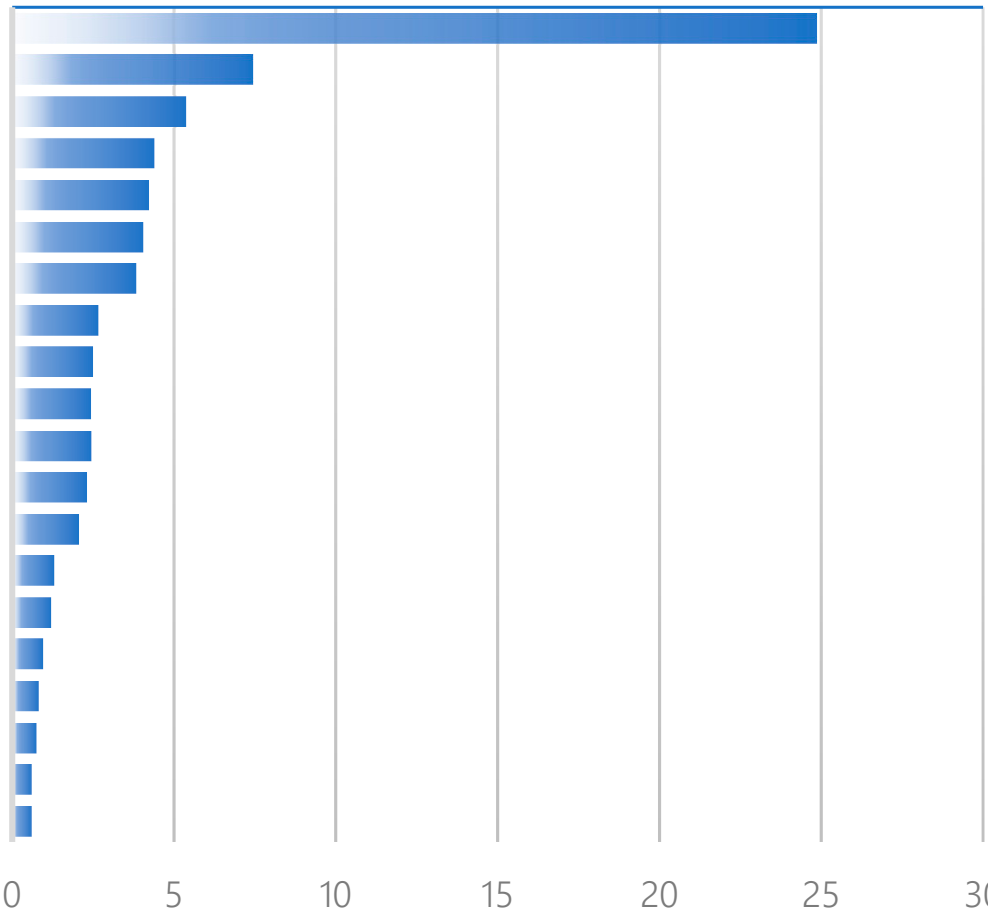

$-\log 10(q)$

Enriched pathways and processes for downregulated proteins in $\mathrm{Hacl} 1^{-1-}$ mouse liver

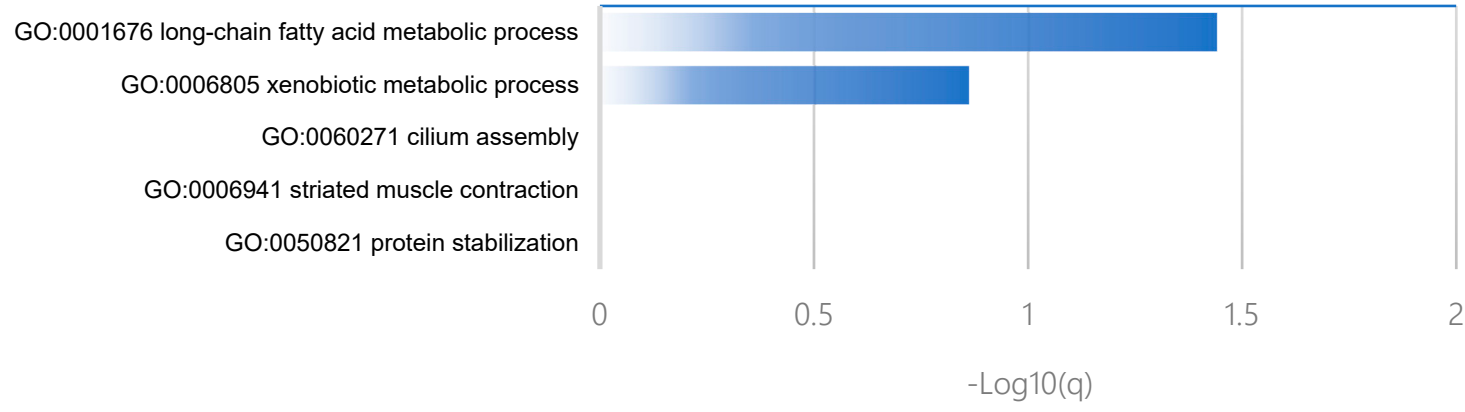

Figure 4. Gene ontology and pathway analysis of upregulated and downregulated proteins in $\mathrm{Hacl1}^{-/-}$mouse liver. 
Table 1. KEGG pathway analysis of upregulated proteins in $\mathrm{Hacl1}^{-/-}$mouse liver.

\begin{tabular}{|c|c|c|c|}
\hline KEGG Pathway & Count & $p$-Value & Gene \\
\hline Peroxisome & 22 & $1.60 \times 10^{-25}$ & $\begin{array}{l}\text { Pecr, Gstk1, Acot8, Pex19, Abcd3, Acsl1, Pex11a, Ephx2, } \\
\text { Eci2, Ech1, Hsd17b4, Pipox, Acaa1b, Acaa1a, Amacr, Acox1, } \\
\text { Ehhadh, Cat, Decr2, Agxt, Crat, Nudt12 }\end{array}$ \\
\hline Fatty acid degradation & 9 & $1.30 \times 10^{-8}$ & $\begin{array}{l}\text { Aldh3a2, Acs11, Acox1, Ehhadh, Cyp4a10, Eci2, Acaa1b, } \\
\text { Cyp4a14, Acaa1a }\end{array}$ \\
\hline $\begin{array}{l}\text { Biosynthesis of unsaturated } \\
\text { fatty acids }\end{array}$ & 6 & $4.30 \times 10^{-6}$ & Pecr, Acox1, Acaa1b, Scd1, Acaa1a, Acot4 \\
\hline Fatty acid metabolism & 7 & $7.00 \times 10^{-6}$ & Pecr, Acsl1, Acox1, Ehhadh, Acaa1b, Scd1, Acaa1a \\
\hline PPAR signaling pathway & 8 & $8.60 \times 10^{-6}$ & $\begin{array}{l}\text { Acsl1, Acox1, Ehhadh, Cyp4a10, Acaa1b, Cyp4a14, Scd1, } \\
\text { Acaa1a }\end{array}$ \\
\hline Metabolic pathways & 25 & $3.40 \times 10^{-4}$ & $\begin{array}{c}\text { Hsd17b4, H2-Ke6, Acaa1b, Acaa1a, Plb1, Cyp2c55, Rdh16, } \\
\text { Dlat, Acot8, Acs11, Ephx2, Cyp4a10, Pmm2, Pipox, Cyp4a14, } \\
\text { Kmo, Aldh3a2, Amacr, Acox1, Ehhadh, Agxt, Gart, Mgll, } \\
\text { Acot4, Uox }\end{array}$ \\
\hline $\begin{array}{l}\text { alpha-Linolenic acid } \\
\text { metabolism }\end{array}$ & 4 & $1.60 \times 10^{-3}$ & Acox1, Acaa1b, Acaa1a, Plb1 \\
\hline $\begin{array}{l}\text { Valine, leucine and isoleucine } \\
\text { degradation }\end{array}$ & 5 & $1.70 \times 10^{-3}$ & Aldh3a2, Ehhadh, Acaa1b, Acaa1a, Aacs \\
\hline Arachidonic acid metabolism & 5 & $9.50 \times 10^{-3}$ & Сyp2c55, Ephx2, Сyp4a10, Cyp4a14, Plb1 \\
\hline Tryptophan metabolism & 4 & $9.50 \times 10^{-3}$ & Aldh3a2, Ehhadh, Cat, Kmo \\
\hline Primary bile acid biosynthesis & 3 & $9.50 \times 10^{-3}$ & Acot8, Amacr, hsd17b4 \\
\hline Lysine degradation & 4 & $1.30 \times 10^{-2}$ & Aldh3a2, Setd2, Ehhadh, Pipox \\
\hline Retinol metabolism & 4 & $5.00 \times 10^{-2}$ & Cyp2c55, Сyp4a10, Rdh16, Сyp4a14 \\
\hline Pyruvate metabolism & 3 & $5.10 \times 10^{-2}$ & Aldh3a2, Acot12, Dlat \\
\hline Carbon metabolism & 4 & $9.50 \times 10^{-2}$ & Ehhadh, Cat, Dlat, Agxt \\
\hline
\end{tabular}

A protein-protein interaction enrichment analysis was performed on differentially regulated proteins. The upregulated proteins mainly form one large cluster associated with peroxisomal protein localisation as part of the peroxisome pathway (Figure 5). Three other clusters are formed associated with the arachidonic acid metabolism, membrane trafficking, and translation (Figure 5).

Three Cyp4a proteins involved in $\omega$-oxidation were identified, as follows: Cyp4a10, Cyp4a12a/b, and Cyp4a14. Only Cyp4a10 and Cyp4a14 were upregulated in the knockout liver, whereas Cyp4a12 expression was not significantly different. The Cyp4a proteins are also associated with the arachidonic acid and retinol metabolism pathways which were both enriched and also share Cyp2c55 (Table 1). In the arachidonic acid metabolism pathway, Ephx2, and Plb1 were also upregulated while Cyp2b9 and Cyp4f14 were downregulated (Table 1). 
MCODE 1
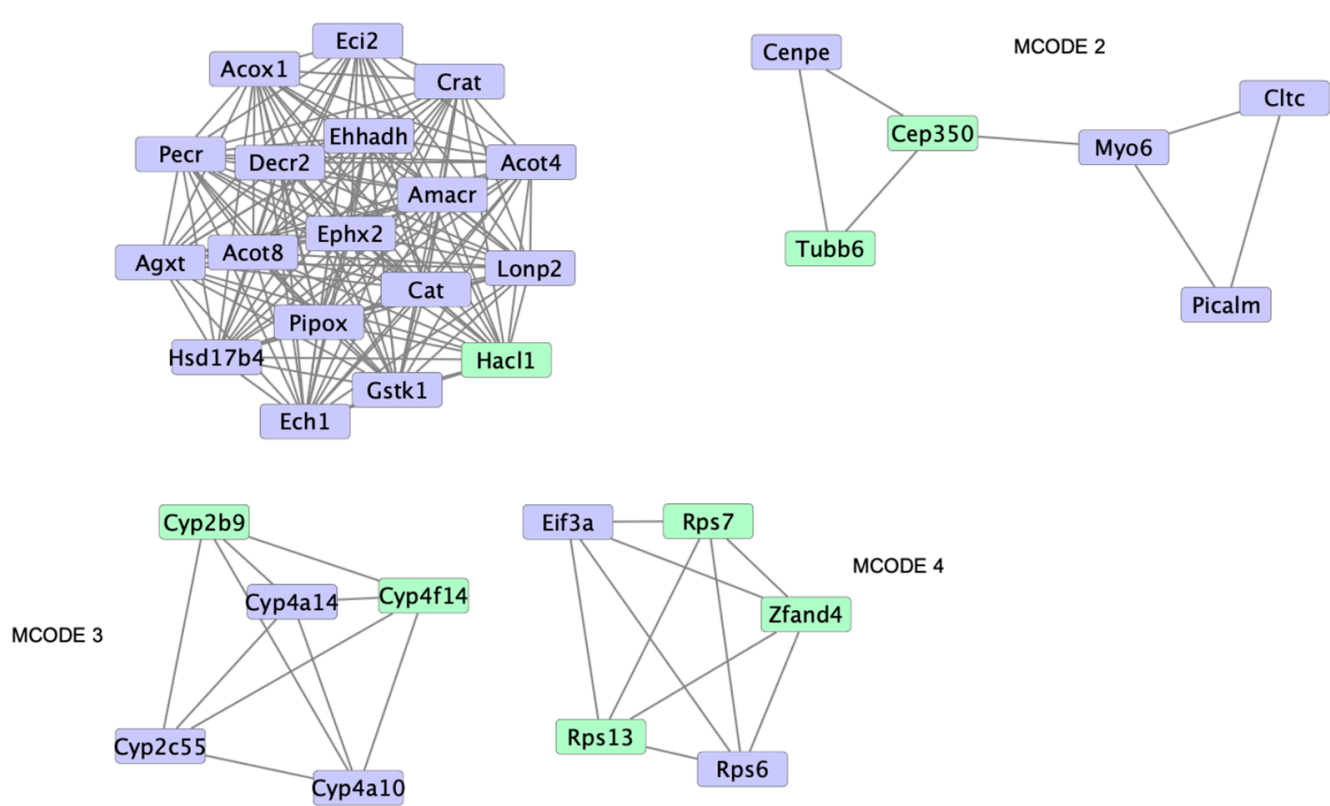

MCODE_1 R-MMU-9033241 Peroxisomal protein import -46.5 *

MCODE_1 R-MMU-9609507 Protein localization -42.3MCODE_1 ko04146 Peroxisome -36.9

MCODE_2 R-MMU-2132295 MHC class II antigen presentation -5.6

MCODE 2 GO:0031623 receptor internalization -5.3

MCODE_2 R-MMU-199991 Membrane Trafficking -5.2

MCODE_3 GO:0019369 arachidonic acid metabolic process -12.2

MCODE_3 ko00590 Arachidonic acid metabolism -11.9

MCODE 3 mmu00590 Arachidonic acid metabolism -11.9

MCODE_4 R-MMU-72695 Formation of the ternary complex, and subsequently, the 43S complex -9.8

MCODE_4 R-MMU-72649 Translation initiation complex formation -9.6

MCODE_4 R-MMU-72702 Ribosomal scanning and start codon recognition -9.6

${ }^{*} \log 10(\mathrm{P})$

Figure 5. Protein-protein interaction enrichment analysis showing physical interactions formed among the upregulated (blue) and downregulated (yellow) proteins in $\mathrm{Hacl1}^{-/}$liver.

\section{4. $\mathrm{Hacl1}^{-/-}$Mouse Kidney Proteome}

A total of 3267 proteins were identified in the kidneys with 16 proteins significantly differentially regulated by at least 1.5 -fold $(p<0.01)$ (Figure $3 \mathrm{~A}, \mathrm{~B})$. Of these, 13 proteins were upregulated and 3 were downregulated in the Hacl1-/- kidney. Gene ontology enrichment analysis revealed five of the upregulated proteins Scp2, Zadh2, Hsd17b4, Crot, and Acsl3 are peroxisomal (Table 2). The KEGG pathway analysis revealed enrichment of the peroxisome, primary bile acid biosynthesis and PPAR signaling pathways (Table 2). The protein-protein interaction enrichment analysis of the upregulated proteins showed the formation of a network between Acsl3, Hsd17b4, and Scp2 associated with Beta-oxidation of pristanoyl-CoA (R-MMU-389887), peroxisomal lipid metabolism (R-MMU-390918), and peroxisomal protein import (R-MMU-9033241) (Figure S7). Hacl1 peptides were identified in the wild-type but with lower abundance than in liver. However, an identification was also made of these peptides in some of the knockout kidneys with no significant difference in abundance with the wild-type. The Hacl1 protein was not detected by Western blot in the knockouts (Figure S1). Hence, we suspect that the detection of these peptides in the knockouts is explained similarly as those detected in the knockout liver. Cyp4a10 and Cyp4a14 were also detected in both groups but with no significant difference in their expression. 
Table 2. Gene Ontology and KEGG pathway analysis of upregulated proteins in Hacl1 ${ }^{-1-}$ mouse kidney.

\begin{tabular}{|c|c|c|}
\hline & $p$-Value & Genes \\
\hline \multicolumn{3}{|l|}{ GO Biological Process } \\
\hline Fatty acid metabolic process & $2.60 \times 10^{-3}$ & Acsl3, Crot, Hsd17b4 \\
\hline Lipid metabolic process & $2.10 \times 10^{-2}$ & Acsl3, Crot, Hsd17b4 \\
\hline Fatty acid beta-oxidation & $2.20 \times 10^{-2}$ & Crot, Hsd17b4 \\
\hline \multicolumn{3}{|l|}{ GO Cellular Compartment } \\
\hline Peroxisome & $6.00 \times 10^{-7}$ & $\begin{array}{c}\text { Acsl3, Crot, Hsd17b4, Scp2, } \\
\text { Zadh2 }\end{array}$ \\
\hline $\begin{array}{c}\text { Intracellular } \\
\text { membrane-bounded organelle }\end{array}$ & $7.30 \times 10^{-3}$ & Acsl3, Crot, Hsd17b4, Scp2 \\
\hline Mitochondrion & $1.20 \times 10^{-2}$ & $\begin{array}{c}\text { Acsl3, Crot, Hsd17b4, Scp2, } \\
\text { Zadh2 }\end{array}$ \\
\hline Peroxisomal membrane & $2.90 \times 10^{-2}$ & Acsl3, Hsd17b4 \\
\hline \multicolumn{3}{|l|}{ GO Molecular Function } \\
\hline Receptor binding & $1.40 \times 10^{-2}$ & Crot, Hsd17b4, Scp2 \\
\hline Actin filament binding & $5.90 \times 10^{-2}$ & Myo1b, Svil \\
\hline $\begin{array}{l}\text { Transferase activity, } \\
\text { transferring acyl groups }\end{array}$ & $7.40 \times 10^{-2}$ & Crot, Scp2 \\
\hline \multicolumn{3}{|l|}{ KEGG Pathway } \\
\hline Peroxisome & $1.20 \times 10^{-6}$ & Acsl3, Crot, Hsd17b4, Scp2 \\
\hline Primary bile acid biosynthesis & $6.20 \times 10^{-3}$ & Hsd17b4, Scp2 \\
\hline PPAR signaling pathway & $3.10 \times 10^{-2}$ & Acsl3, Scp2 \\
\hline Metabolic pathways & $7.30 \times 10^{-2}$ & Acsl3, Hsd17b4, Scp2 \\
\hline
\end{tabular}

\subsection{Hacl1 ${ }^{-1-}$ Mouse Brain Proteome}

A total of 1434 proteins were identified in the mouse brains and there were no significant differences in their expression in the wild-type and $\mathrm{Hacl1}^{-/-}$groups (Figure 3A). Neither Hacl1 nor the $\omega$-oxidation Cyp4a proteins were identified in either group.

\section{Discussion}

In agreement with the results obtained by Mezzar et al. [11], this study found that Hacl1 deficient mice fed a high phytol diet had significantly higher hepatic levels of phytanic and 2-hydroxyphytanic acid and significantly lower hepatic levels of heptadecanoic acid (C17:0) than controls fed the same diet. The mean phytanic acid content (expressed as ng/mg liver) was 2.4-fold higher, whereas the mean 2-hydroxyphytanic acid was 55-fold higher. This is consistent with defective $\alpha$-oxidation of phytanate at the level of 2-hydroxyacyl-CoA ligase. In contrast, in Refsum disease, there is no accumulation of 2-hydroxyphytanic acid [17]. It therefore behoves us to consider whether the profound changes in gene expression revealed by the liver proteomic analysis owes more to the accumulation of 2-hydroxyphytanic acid than that of phytanic acid. Studies of 2-hydroxyphytanic acid as a PPAR $\alpha$ agonist would be interesting. Furthermore, the low content of heptadecanoic acid in the Hacl1 ${ }^{-1-}$ livers is consistent with significant synthesis of odd-chain fatty acids from 2-hydroxyfatty acids [11].

Hacl1 knockout mice did not develop any notable phenotypes in our investigation compared with Mezzar et al. [11], in which they observed weight loss, an enlarged mottled liver, reduced hepatic glycogen and triglycerides, and no abdominal white adipose tissue. These outcomes could be explained by the different background strain used in our study that would account for most of the variation. In addition, mice in our study were fed a 
lower phytol diet $(0.2 \% w / w)$ over 10 weeks in their home cage, which may also attribute to the absence of phenotypes found herein.

In this study, we have used a proteomics approach to study the activation of an alternative pathway for phytanic acid oxidation through upregulation of cytochrome P450 enzymes involved in fatty acid $\omega$-oxidation, peroxisome proliferation and upregulation of a transporter and enzymes involved in $\beta$-oxidation of dicarboxylic acids. This upregulation also correlates with the reported identification of metabolic intermediates of phytanic acid $\omega$ - and $\beta$-oxidation in Hacl1 ${ }^{-l-}$ mice [11]. Phytanic acid is known to activate PPAR $\alpha$ [18], thus it is reasonable to expect its accumulation will induce $\omega$-oxidation, peroxisome proliferation and increased expression of peroxisomal $\beta$-oxidation enzymes. In Refsum patients, $\omega$-plus $\beta$-oxidation of phytanic acid is evident by the detection of urinary 3-methyladipic acid [19]. It remains unclear if accumulating 2-hydroxyphytanic acid can also act as a PPAR $\alpha$ agonist or as an agonist for RXR, the PPAR co-activator.

The first step in the alternative pathway is $\omega$-oxidation. This study showed that in the livers of phytol-fed $\mathrm{Hacl1}^{-I-}$ mice there was upregulation of the $\omega$-oxidation enzymes Cyp4a10 and Cyp4a14 but not Cyp4a12. This is consistent with the upregulation being mediated by PPAR signaling. It has been shown in mouse liver and kidney that Cyp4a12 gene expression, unlike Cyp4a10 and Cyp4a14, is not induced by fibrates [20]. After generation of dicarboxylic acids by the Cyp4a10 and Cyp4a14, the next step in the alternative pathway is the formation of the dicarboxylyl-CoA ester, which then needs to be transported into the peroxisomes. The transporter that accomplishes import of dicarboxylyl-CoA esters and branched chain acyl-CoA esters is Abcd3 [21,22]. In this study, Abcd3 was upregulated in the livers of $\mathrm{Hacl1}^{-1-}$ mice fed a high phytol diet. Peroxisomal $\beta$-oxidation of dicarboxylic acids is catalysed by acyl-CoA oxidase 1 (Acox1), the peroxisomal L-bifunctional protein and the Acaa1b thiolase [22]. Expression of all three enzymes was upregulated in the livers of $\mathrm{Hacl1}^{-I-}$ mice fed a high phytol diet. The export of medium chain dicarboxylyl-CoA esters from the peroxisomes is achieved by conversion to carnitine by the peroxisomal carnitine O-octanoyl transferase (Crot). This study showed that expression of this enzyme was increased in the livers of $\mathrm{Hacl1}^{-1-}$ fed a high phytol diet.

In summary, therefore, a proteomic analysis of livers from $\mathrm{Hacl1}^{-/-}$and $\mathrm{Hacl1}^{+/+}$ mice fed a high phytol diet has shown that every protein required for the oxidation of phytanic acid by the alternative pathway of $\omega$-oxidation followed by peroxisomal import, peroxisomal $\beta$-oxidation and peroxisomal export is upregulated in the $\mathrm{Hacl1}^{-1-}$ animals. There is strong evidence for the involvement of PPAR $\alpha$ in this process. Phytanic acid is a known PPAR $\alpha$ agonist and the level of phytanic acid was 2.4-fold higher in the Hacl1-llivers. There was a much more substantial build-up of 2-hydroxyphytanic acid in the $\mathrm{Hacl1}^{-1-}$ livers (55-fold) but whether this compound activates PPAR $\alpha$ or an X receptor (such as RXR) is not known.

It was not only the alternative pathway for phytanic acid oxidation that was differentially regulated in $\mathrm{Hacl1}^{-/-}$livers. Several proteins associated with the arachidonic acid (AA) metabolism pathway were also differentially regulated. It was recently shown that the PPAR $\alpha$ agonist, clofibrate, increases molecular species of phosphatidylethanolamine containing arachidonic acid for biogenesis of peroxisomal membranes in peroxisome proliferation in the liver [23]. The downregulated monooxygenase Cyp4f14, orthologue for human CYP4F12, is involved in the w-hydroxylation of arachidonic acid to 20hydroxyeicosatetraenoic acid [24], while Cyp2b9, also downregulated, is the orthologue for humans CYP2B6, and involved in arachidonic acid epoxidation [25]. Thus, downregulation of both these enzymes could reduce catabolism of arachidonic acid allowing for increased synthesis of phosphatidylethanolamines containing AA. For Cyp4f14, the mechanism may not involve a direct effect of PPAR $\alpha$ since, although PPAR $\alpha$ regulates CYP4A enzymes, it does not have control over the CYP4F enzymes. Instead, CYP4F12 is regulated by pregnane-X receptor (PXR) in human hepatocytes [26]. On the other hand, CYP2B6 can be regulated by PPAR $\alpha, P X R$, and constitutive androstane receptor (CAR) [25-27]. Many exogeneous and endogenous ligands have been identified as activators and few as 
inhibitors of PXR and CAR [28]. These include stigmasterol and docosahexaenoic acid which inhibit PXR and CAR activity, respectively. However, Cyp2c55 is also regulated by PXR and CAR and is upregulated in Hacl1 ${ }^{-l-}$ liver. Thus, it seems unlikely that PXR and CAR activity is partially inhibited in $\mathrm{Hacl1}^{-1-}$ mice on a high phytol diet and suggests Cyp4f14 and Cyp2b9 suppression is not PXR and/or CAR dependent. Nevertheless, further investigation on the effect of diterpenoids and phytanic acid on PXR and CAR activity is needed. The Hacl1 ${ }^{-I-}$ mice showed upregulation of two enzymes involved in AA metabolism. Upregulation of phospholipase B1 (Plb1) would be consistent with increased supply of AA from phosphatidylcholines to allow for synthesis of phosphoethanolamines containing AA. The reason for upregulation of the epoxide hydrolase (Ephx) is not clear.

The kidney proteome indicated an insignificant difference in the expression of Hacl1 in the wild-type and $\mathrm{Hacl1}^{-1-}$ mouse, expectedly since the liver peroxisomes are the main site for $\alpha$-oxidation and Hacl1 expression is relatively low in kidney peroxisomes [29]. Moreover, in contrast to the liver, Hacl1 ${ }^{-1-}$ kidney expression of Cyp4a10 and Cyp4a14 was not elevated suggesting $\omega$-oxidation is not necessarily activated. One possible explanation is the presence of the peroxisomal hydroxyacid oxidase 2 (Hao2) which is mainly expressed in kidneys and is active towards 2-hydroxypalmitic acid converting it to 2-oxo-palmitic acid [30], with possible activity towards 2-hydroxyphytanic acid [31]. However, there was no significant difference in Hao2 expression in $\mathrm{Hacl1}^{-1-}$ kidney. This and the low expression of Hacl1 in kidney peroxisomes suggests Hao2, and not Hacl1, is primarily active in 2-hydroxyphytanic acid oxidation. The Hao2 activity has been shown to be comparable in male and female Hacl1 ${ }^{-l-}$ kidney on high phytol diet [11]. On the other hand, an endoplasmic reticulum lyase resembling bacterial acetolactate synthase has been recently described. It shares substrate specificity with HACL1 and has been reported to have higher activity in $\mathrm{Hacl1}^{-1-}$ kidney compared to liver [11]. However, peptides for this lyase were not identified in our kidney analysis of both wild-type and knockouts. Since only 13 proteins were significantly upregulated in the $\mathrm{Hacl1}^{-1-}$ kidney, a few GO processes and KEGG pathway terms were enriched. The upregulated peroxisomal proteins Acsl3, Crot, Hsd17b4, and Scp2 are mediated by PPAR $\alpha[32,33]$.

The Hacl1 ${ }^{-1-}$ brain proteome showed no significant difference in protein expression. More so, Hacl1 was not detected, which is in agreement with published data that shows Hacl1 mRNA to be virtually undetectable in the mouse brain [34]. None of the Cyp4a proteins detected and elevated in the liver where detected in the brain, which is also consistent with mRNA expression studies showing mouse brain Cyp4a10, Cyp4a12, and Cyp4a14 relative expression to be very low [35]. Cerebronic acid (2OH-C24:0) is a major 2-hydroxylated fatty acid component of cerebrosides and sulfatides in the brain and nervous tissues that undergoes peroxisomal $\alpha$-oxidation. However, the enzymes involved in cerebronic acid $\alpha$-oxidation are distinct from those involved in phytanic acid $\alpha$-oxidation. As a result, Refsum disease patient fibroblasts do not show an impairment of cerebronic acid $\alpha$-oxidation [36]. Similarly, Hacl1 ${ }^{-1}$ mice fed a phytol diet show no change in their fatty acid profile [11]. Both the levels of the major 2-hydroxylated fatty acids exclusively located in nervous tissues and the odd chain fatty acids are unaffected in these mice. This, along with our proteomic findings, further support the existence of an alternate $\alpha$-oxidation pathway for 2-hydroxylated fatty acids in the brain with an acyl-CoA lyase distinct from HACL1 [11,36].

Mutations directly associated with the peroxisomal fatty acid $\alpha$-oxidation pathway are extremely rare, with an estimated 1 in $10^{6}$ incidence of Refsum disease in the UK [37], while only a handful of AMACR deficient patients have been reported in the literature. So far, there has been no definite report of a HACL1 deficient patient, although HACL1 was one of 57 candidate genes for a recessive syndrome involving intellectual disability, muscle weakness and a characteristic face [38]. However, we speculate that the alternative pathway activated in Hacl1 deficient mice may also be activated in humans, resulting in the lack of a clear peroxisomal metabolic disorder phenotype, hence the absence of an identified case. 
In summary, this study provides an insight into the mechanisms by which an alternative pathway is activated as a result of Hacl1 deficiency and validates previous findings on PPAR $\alpha$ and Cyp4a involvement. Discovery proteomic studies are lacking in Refsum and Amacr-deficient mouse models thus studying their proteome could provide better understanding of disease mechanism and potentially drug targeting. This study is intended as a resource for further investigation into disorders associated with peroxisomal fatty acid alpha-oxidation and demonstrates the power of metabolomic and proteomic approaches in studying metabolic pathways.

Supplementary Materials: The supporting information can be downloaded at: https:/ /www.mdpi. com/article/10.3390/ijms23020987/s1.

Author Contributions: Conceptualization, D.P.G. and P.T.C.; methodology, Y.K, F.M., K.M., P.T.C. and D.P.G.; investigation, Y.K., S.C., F.L., A.F., H.V.L., F.M., S.F., N.R., G.B., D.C., C.A., A.R.H., A.B., T.N. and R.A.-S.; writing—original draft preparation, Y.K.; writing—review and editing, W.H., K.M. and P.T.C.; supervision, P.P., P.T.C. and D.P.G.; funding acquisition, D.P.G. All authors have read and agreed to the published version of the manuscript.

Funding: This research was funded by Rosetrees Trust (Grant M260-CD1) and St Peter's Trust for Kidney, Bladder and Prostate Research.

Institutional Review Board Statement: The animal study protocol was approved by the Animal Welfare Ethical Review Body (AWERB) of MRC Harwell Institute (Project License: 30/3070 in 2015).

Data availability statement: The raw mass spectrometric data has been deposited in the UCL Research Data Repository. The proteomics dataset can be accessed by visiting https:/ / doi.org/10.552 2/04/17025359, accessed on 15 December 2021.

Conflicts of Interest: The authors declare no conflict of interest.

\section{References}

1. Wanders, R.J.; Komen, J.; Ferdinandusse, S. Phytanic acid metabolism in health and disease. Biochim. Biophys. Acta 2011, 1811, 498-507. [CrossRef] [PubMed]

2. Miura, Y. The biological significance of omega-oxidation of fatty acids. Proc. Jpn. Acad. Ser. B Phys. Biol. Sci. 2013, 89, 370-382. [CrossRef]

3. Komen, J.C.; Duran, M.; Wanders, R.J. Omega-hydroxylation of phytanic acid in rat liver microsomes: Implications for Refsum disease. J. Lipid Res. 2004, 45, 1341-1346. [CrossRef] [PubMed]

4. Komen, J.C.; Duran, M.; Wanders, R.J. Characterization of phytanic acid omega-hydroxylation in human liver microsomes. Mol. Genet. Metab. 2005, 85, 190-195. [CrossRef]

5. Wierzbicki, A.S.; Lloyd, M.D.; Schofield, C.J.; Feher, M.D.; Gibberd, F.B. Refsum's disease: A peroxisomal disorder affecting phytanic acid alpha-oxidation. J. Neurochem. 2002, 80, 727-735. [CrossRef] [PubMed]

6. Brown, P.J.; Mei, G.; Gibberd, F.B.; Burston, D.; Mayne, P.D.; McClinchy, J.E.; Sidey, M. Diet and Refsum's disease. The determination of phytanic acid and phytol in certain foods and the application of this knowledge to the choice of suitable convenience foods for patients with Refsum's disease. J. Hum. Nutr. Diet. 1993, 6, 295-305. [CrossRef]

7. Dry, J.; Pradalier, A.; Canny, M. Refsum's disease: 10 years of a diet low in phytanic acid and phytol. Ann. Med. Intern. 1982, 133, 483-487.

8. Steinberg, D.; Mize, C.E.; Herndon, J.H.; Fales, H.M.; Engel, W.K.; Vroom, F.Q. Phytanic acid in patients with Refsum's syndrome and response to dietary treatment. Arch. Intern. Med. 1970, 125, 75-87. [CrossRef] [PubMed]

9. Ferdinandusse, S.; Zomer, A.W.; Komen, J.C.; van den Brink, C.E.; Thanos, M.; Hamers, F.P.; Wanders, R.J.; van der Saag, P.T.; Poll-The, B.T.; Brites, P. Ataxia with loss of Purkinje cells in a mouse model for Refsum disease. Proc. Natl. Acad. Sci. USA 2008, 105, 17712-17717. [CrossRef] [PubMed]

10. Selkala, E.M.; Nair, R.R.; Schmitz, W.; Kvist, A.P.; Baes, M.; Hiltunen, J.K.; Autio, K.J. Phytol is lethal for Amacr-deficient mice. Biochim. Biophys. Acta 2015, 1851, 1394-1405. [CrossRef]

11. Mezzar, S.; De Schryver, E.; Asselberghs, S.; Meyhi, E.; Morvay, P.L.; Baes, M.; Van Veldhoven, P.P. Phytol-induced pathology in 2-hydroxyacyl-CoA lyase (HACL1) deficient mice. Evidence for a second non-HACL1-related lyase. Biochim. Biophys. Acta Mol. Cell Biol. Lipids 2017, 1862, 972-990. [CrossRef] [PubMed]

12. Skarnes, W.C.; Rosen, B.; West, A.P.; Koutsourakis, M.; Bushell, W.; Iyer, V.; Mujica, A.O.; Thomas, M.; Harrow, J.; Cox, T.; et al. A conditional knockout resource for the genome-wide study of mouse gene function. Nature 2011, 474, 337-342. [CrossRef] 
13. de Angelis, M.H.; Nicholson, G.; Selloum, M.; White, J.K.; Morgan, H.; Ramirez-Solis, R.; Sorg, T.; Wells, S.; Fuchs, H.; Fray, M.; et al. Analysis of mammalian gene function through broad-based phenotypic screens across a consortium of mouse clinics. Nat. Genet. 2015, 47, 969-978. [CrossRef] [PubMed]

14. Bliss, E.; Heywood, W.E.; Benatti, M.; Sebire, N.J.; Mills, K. An optimised method for the proteomic profiling of full thickness human skin. Biol. Proced. Online 2016, 18, 15. [CrossRef] [PubMed]

15. Zhou, Y.; Zhou, B.; Pache, L.; Chang, M.; Khodabakhshi, A.H.; Tanaseichuk, O.; Benner, C.; Chanda, S.K. Metascape provides a biologist-oriented resource for the analysis of systems-level datasets. Nat. Commun. 2019, 10, 1523. [CrossRef] [PubMed]

16. Goedhart, J.; Luijsterburg, M.S. VolcaNoseR is a web app for creating, exploring, labeling and sharing volcano plots. Sci. Rep. 2020, 10, 20560. [CrossRef]

17. ten Brink, H.J.; Schor, D.S.; Kok, R.M.; Poll-The, B.T.; Wanders, R.J.; Jakobs, C. Phytanic acid alpha-oxidation: Accumulation of 2-hydroxyphytanic acid and absence of 2-oxophytanic acid in plasma from patients with peroxisomal disorders. J. Lipid Res. 1992, 33, 1449-1457. [CrossRef]

18. Ellinghaus, P.; Wolfrum, C.; Assmann, G.; Spener, F.; Seedorf, U. Phytanic acid activates the peroxisome proliferator-activated receptor alpha (PPARalpha) in sterol carrier protein 2-/ sterol carrier protein x-deficient mice. J. Biol. Chem. 1999, 274, $2766-2772$. [CrossRef]

19. Wierzbicki, A.S.; Mayne, P.D.; Lloyd, M.D.; Burston, D.; Mei, G.; Sidey, M.C.; Feher, M.D.; Gibberd, F.B. Metabolism of phytanic acid and 3-methyl-adipic acid excretion in patients with adult Refsum disease. J. Lipid Res. 2003, 44, 1481-1488. [CrossRef]

20. Bell, D.R.; Plant, N.J.; Rider, C.G.; Na, L.; Brown, S.; Ateitalla, I.; Acharya, S.K.; Davies, M.H.; Elias, E.; Jenkins, N.A.; et al. Species-specific induction of cytochrome P-450 4A RNAs: PCR cloning of partial guinea-pig, human and mouse CYP4A cDNAs. Biochem. J. 1993, 294, 173-180. [CrossRef]

21. Ferdinandusse, S.; Jimenez-Sanchez, G.; Koster, J.; Denis, S.; Van Roermund, C.W.; Silva-Zolezzi, I.; Moser, A.B.; Visser, W.F.; Gulluoglu, M.; Durmaz, O.; et al. A novel bile acid biosynthesis defect due to a deficiency of peroxisomal ABCD3. Hum. Mol. Genet. 2015, 24, 361-370. [CrossRef] [PubMed]

22. van Roermund, C.W.; Ijlst, L.; Wagemans, T.; Wanders, R.J.; Waterham, H.R. A role for the human peroxisomal half-transporter ABCD3 in the oxidation of dicarboxylic acids. Biochim. Biophys. Acta 2014, 1841, 563-568. [CrossRef]

23. Miura, H.; Mizuguchi, H.; Amano-Iwashita, M.; Maeda-Kogure, R.; Negishi, A.; Sakai, A.; Toyama, T.; Kawai, H.; Mitsumoto, A.; Kudo, N. Clofibric acid increases molecular species of phosphatidylethanolamine containing arachidonic acid for biogenesis of peroxisomal membranes in peroxisome proliferation in the liver. Biochim. Biophys. Acta Mol. Cell Biol. Lipids 2021, 1866, 158963. [CrossRef]

24. Rakhshandehroo, M.; Knoch, B.; Muller, M.; Kersten, S. Peroxisome proliferator-activated receptor alpha target genes. Cell. Mol. Life Sci. CMLS 2004, 61, 393-416. [CrossRef]

25. Shi, C.; Min, L.; Yang, J.; Dai, M.; Song, D.; Hua, H.; Xu, G.; Gonzalez, F.J.; Liu, A. Peroxisome Proliferator-Activated Receptor alpha Activation Suppresses Cytochrome P450 Induction Potential in Mice Treated with Gemfibrozil. Basic Clin. Pharmacol. Toxicol. 2017, 121, 169-174. [CrossRef]

26. Hariparsad, N.; Chu, X.; Yabut, J.; Labhart, P.; Hartley, D.P.; Dai, X.; Evers, R. Identification of pregnane-X receptor target genes and coactivator and corepressor binding to promoter elements in human hepatocytes. Nucleic Acids Res. 2009, 37, 1160-1173. [CrossRef]

27. Chang, T.K.; Bandiera, S.M.; Chen, J. Constitutive androstane receptor and pregnane X receptor gene expression in human liver: Interindividual variability and correlation with CYP2B6 mRNA levels. Drug. Metab. Dispos. 2003, 31, 7-10. [CrossRef]

28. Hernandez, J.P.; Mota, L.C.; Baldwin, W.S. Activation of CAR and PXR by Dietary, Environmental and Occupational Chemicals Alters Drug Metabolism, Intermediary Metabolism, and Cell Proliferation. Curr. Pharm. Person. Med. 2009, 7, 81-105. [CrossRef]

29. Mi, J.; Kirchner, E.; Cristobal, S. Quantitative proteomic comparison of mouse peroxisomes from liver and kidney. Proteomics 2007, 7, 1916-1928. [CrossRef]

30. Jones, J.M.; Morrell, J.C.; Gould, S.J. Identification and characterization of HAOX1, HAOX2, and HAOX3, three human peroxisomal 2-hydroxy acid oxidases. J. Biol. Chem. 2000, 275, 12590-12597. [CrossRef]

31. Draye, J.P.; Van Hoof, F.; de Hoffmann, E.; Vamecq, J. Peroxisomal oxidation of L-2-hydroxyphytanic acid in rat kidney cortex. Eur. J. Biochem. 1987, 167, 573-578. [CrossRef]

32. Jia, Y.; Qi, C.; Zhang, Z.; Hashimoto, T.; Rao, M.S.; Huyghe, S.; Suzuki, Y.; Van Veldhoven, P.P.; Baes, M.; Reddy, J.K. Overexpression of peroxisome proliferator-activated receptor-alpha (PPARalpha)-regulated genes in liver in the absence of peroxisome proliferation in mice deficient in both L- and D-forms of enoyl-CoA hydratase/dehydrogenase enzymes of peroxisomal beta-oxidation system. J. Biol. Chem. 2003, 278, 47232-47239. [CrossRef]

33. Kersten, S. Integrated physiology and systems biology of PPARalpha. Mol. Metab. 2014, 3, 354-371. [CrossRef]

34. Huyghe, S.; Casteels, M.; Janssen, A.; Meulders, L.; Mannaerts, G.P.; Declercq, P.E.; van Veldhoven, P.P.; Baes, M. Prenatal and postnatal development of peroxisomal lipid-metabolizing pathways in the mouse. Biochem. J. 2001, 353, 673-680. [CrossRef]

35. Yamaori, S.; Jiang, R.; Maeda, C.; Ogawa, R.; Okazaki, H.; Aramaki, H.; Watanabe, K. Expression levels of 39 Cyp mRNAs in the mouse brain and neuroblastoma cell lines, C-1300N18 and NB2a-strong expression of Cyp1b1. Fundam. Toxicol. Sci. 2017, 4, 195-200. [CrossRef]

36. Sandhir, R.; Khan, M.; Singh, I. Identification of the pathway of alpha-oxidation of cerebronic acid in peroxisomes. Lipids 2000, 35, 1127-1133. [CrossRef] 
37. Wanders, R.J.A.; Waterham, H.R.; Leroy, B.P. Refsum Disease. In GeneReviews ${ }^{\circledR}$; Adam, M.P., Ardinger, H.H., Pagon, R.A., Wallace, S.E., Bean, L.J.H., Mirzaa, G., Amemiya, A., Eds.; University of Washington: Seattle, WA, USA, 1993.

38. Kariminejad, A.; Nafissi, S.; Nilipoor, Y.; Tavasoli, A.; Van Veldhoven, P.P.; Bonnard, C.; Ng, Y.T.; Majoie, C.B.; Reversade, B.; Hennekam, R.C. Intellectual disability, muscle weakness and characteristic face in three siblings: A newly described recessive syndrome mapping to 3p24.3-p25.3. Am. J. Med. Genet. A 2015, 167, 2508-2515. [CrossRef] 